\title{
Expression of Narcissus pseudonarcissus lectin and mannose receptor positive macrophages predict progression and prognosis of patients with gastric cancer
}

\author{
Sheng-Sheng Liu ${ }^{1}$, Yi Gao ${ }^{1}$, Shui-Ping Yin ${ }^{2}$, Lei Ye ${ }^{3}$, Zi-Jian Song ${ }^{4}$, Qian Liu ${ }^{1}$, Song-Guo Li ${ }^{1}$, Wei-Dong Du ${ }^{1}$ \\ ${ }^{1}$ Department of Pathology, School of Basic Medicine, Anhui Medical University, Hefei, China; ${ }^{2}$ Department of Urology, ${ }^{3}$ Department of \\ Neurosurgery, the First Affiliated Hospital of Anhui Medical University, Hefei, China; ${ }^{4}$ Department of Orthopaedics, the First People's Hospital of \\ Xuzhou, Xuzhou, China \\ Contributions: (I) Conception and design: WD Du, SS Liu; (II) Administrative support: WD Du; (III) Provision of study materials or patients: SS Liu, \\ Y Gao, L Ye; (IV) Collection and assembly of data: SS Liu, SP Yin, L Ye; (V) Data analysis and interpretation: SS Liu, ZJ Song, Q Liu, SG Li; (VI) \\ Manuscript writing: All authors; (VII) Final approval of manuscript: All authors. \\ Correspondence to: Wei-Dong Du. Department of Pathology, Anhui Medical University, Meishan 81, Hefei 230032, China. \\ Email: weidong.du@ahmu.edu.cn.
}

Background: Mannose receptor (MR) is an immune adhesion molecule and is mainly expressed in macrophages and nonmature dendritic cells. The ligand mannose, one of the natural ligands of MR, is a monosaccharide, which is localized in the envelope or cytoplasm of macrophages. The aim of this study was to investigate expression of MR and its ligand mannose in tumor tissues of primary advanced gastric cancer and to evaluate the predictive and prognostic value of the positive cells in gastric cancer patients.

Methods: Histochemical staining for Narcissus pseudonarcissus lectin (NPL) and immunohistochemical envision two-step assay for MR were used to detect expression of NPL and MR in primary advanced gastric adenocarcinoma tissues. Adjacent non-cancerous gastric tissues of the patients were used as controls. Relationship of NPL and MR expression in the tumor tissues with clinicopathological features and survival time of the gastric cancer patients were analyzed.

Results: Numbers of $\mathrm{NPL}^{+}$and $\mathrm{MR}^{+}$macrophages in stromal tissues of gastric cancer were significantly higher than those in the adjacent non-cancerous gastric tissues $(\mathrm{P}=0.006 ; \mathrm{P}<0.001)$. NPL expression in the primary tumor tissues was significantly more dominant than that in the adjacent non-cancerous gastric tissues $(\mathrm{P}=0.003)$. Expression of both the molecules in macrophages in tumor tissues was negatively correlated $(\mathrm{r}=-0.363, \mathrm{P}=0.009)$. TNM stage of the patients was closely correlated to number of $\mathrm{MR}^{+}$macrophages and NPL expression in the stromal tissues of gastric cancer $(\mathrm{P}=0.009$ and $\mathrm{P}=0.020)$. Kaplan-Meier survival model data showed that the patients with low counting of $\mathrm{NPL}^{+}$macrophages and high counting of $\mathrm{MR}^{+}$ macrophages significantly led to worse disease progression and poorer prognosis $(\mathrm{P}=0.008)$. Cox regression analysis further demonstrated that high expression of $\mathrm{MR}^{+}$macrophages was an independent predictor of poor prognosis in patients with gastric cancer $(\mathrm{P}=0.033)$.

Conclusions: Occurrence of mannose and MR in tumor tissues of gastric cancer might be prognostic factors for estimating risk of gastric cancer patients.

Keywords: Mannose receptor (MR); CD206; mannose, Narcissus pseudonarcissus lectin (NPL); gastric cancer; prognosis

Submitted Mar 12, 2020. Accepted for publication Aug 21, 2020.

doi: $10.21037 /$ tcr-20-1459

View this article at: http://dx.doi.org/10.21037/tcr-20-1459 


\section{Introduction}

Gastric cancer is the fifth most common malignant tumor and the third leading cause of cancer death worldwide (1). There are highest morbidity and mortality in East Asia area, such as South Korea, Mongolia, Japan, and China, and becomes the second most deadly cancer entity in China (2). Although huge advances have been made in the diagnosis and treatment of gastric cancer, the survival of patients is still poor, especially in the patients at the advanced stage of gastric cancer (3). In addition, the current TNM classification cannot fully reflect the tumor biological behavior and prognosis for patients with gastric cancer (4). Therefore, there is an urgent need to identify more sensitive biomarkers that objectively predict tumor progression and patient survival, as well as to provide potential modalities to treatment of the tumor.

Mannose receptors (MR, also CD206) (5), is a subgroup of the $\mathrm{C}$ type lectin superfamily. As a transmembrane receptor, it especially recognizes saccharide chains terminating in mannose, fucose or $\mathrm{N}$-acetylglucosamine. MR was expressed mainly on the surface of tissue macrophages and less in hepatic and lymphatic endothelia, glomerular mesangial cells in the kidneys, tracheal smooth muscle cells and retinal pigment epithelium (6). MR has the function of regulating homeostasis, mediating innate and acquired immune responses, and organically combining these immune responses together by endocytosis $(6,7)$. MR is involved in the body's tumor immunity, tumor metastasis, and immune evasion in the tumor microenvironment by recognition of different tumor-associated antigens (8-10). Previous studies revealed that MR, as an immunoadhesive molecule, was abnormally overexpressed in tumor stromal tissues, potentially affecting carcinogenesis, development and prognosis of patients (11-14). Although a recent investigation demonstrated that MR was highly expressed in gastric cancer cell lines as well as tissue samples of gastric cancer and was considered an independent predicting factor for poor prognosis of gastric cancer patients (15), more evidences indicated that gastric cancer itself presented no expression of MR $(16,17)$. Rather, a previous study showed that MR was expressed only in macrophages of gastric cancer tissues and would be a poor prognostic factor for gastric cancer patients (16). On the other hand, tumorassociated macrophage surfaces (TAMs), in particular in M2 macrophages, are rich in $\mathrm{MR}$, which is widely recognized as a specific marker for M2 macrophages (18-20). MRtagged M2 macrophages often infiltrate in the stromal tissues of tumors (21). However, the potential effect of MRtagged M2 macrophages in the advanced gastric cancer and its prognosis remains controversial $(16,22)$. Thus, it is necessary to further investigate potential effects of MR expression on clinicopathological outcome in patients with gastric cancer.

Mannose, one of the natural ligands for the MR, is a monosaccharide, which is expressed in the envelope or cytoplasm of macrophages $(23,24)$, and plays a key role in human metabolism, especially in the glycosylation of proteins (25). Mannose is required for $\mathrm{N}$-glycosylation and glycophospholipid anchoring synthesis. A variety of cancers are often involved in aberrant glycosylation. Changes in glycosylation may be associated with signaling pathways during malignant transformation. The previous investigations found that levels of serum mannose increased in patients with esophageal adenocarcinoma and breast cancer $(26,27)$. As a member of the large family of mannosebinding proteins, Narcissus pseudonarcissus lectin (NPL) is a molecule from monocotyledons such as Amaryllidaceae, Liliaceae, Onion, Orchidaceae and Araceae (28). NPL exhibits a characteristic with an $\alpha$-D-mannose specific conjugation and preferable binding to $\alpha-1,3$ or $\alpha-1,6$ linked mannose, which has the highest affinity towards oligomeric saccharides on glycoproteins (29). The expression of carbohydrate chain on the surface of gastric normal mucosal epithelial cells and gastric cancer cells had been detected by a NPL-based lectin chip (30). Like MR, NPL is also expressed in macrophages, which are rich in mannose sugar chains on the surface of activated macrophages $(24,31,32)$. However, there are no evidences indicating whether NPL is involved in pathogenesis of gastric cancer.

In the microenvironment of solid tumors, macrophages are the most abundant immune cells and take part in the pro-inflammatory effects of tumors. Activated M2 macrophages enable the ability to promote tumor growth, angiogenesis, invasion, metastasis, and immunosuppressive $\mathrm{T}$ cell production. Thus, it was believed that M2 macrophages promoted tumor progression (21) and was used as a prognostic marker for various tumors (33). It was demonstrated that macrophages were able to mediate a endocytosis effect when MR on its surfaces integrated the terminal mannosyl unit on extracellular lipid mannan (LM) of Mycobacterium tuberculosis (34). Also, recognition of MR to its ligand-mannose promoted the phagocytic effect of macrophages (33) and induced macrophages to secrete cytokines such as IL-12, TNF- $\alpha$ and IFN- $\gamma$ (35). It was suggested that expression of MR and its ligand mannose 
in gastric cancer tissues might be a valuable predictor of cancer invasiveness and prognosis $(36,37)$. However, the investigations have been lacked that carry out a comparative observation of expressions of MR and mannose in gastric cancer tissues. Thus, studies regarding effects of mannose and MR expression on the clinical progression and prognosis in gastric cancer patients were still expected. In this study, we performed an immunohistochemical staining for MR-derived cells and NPL lectin histochemical staining for its ligand mannose (via NPL)-derived cells and gastric cancerous tissues. We further analyzed relationship between expressions of MR and its ligand-mannose in gastric cancer tissues and addressed associations of the biomarkers and clinical and pathological features of the patients as well as effects on prognostic value for the gastric cancer patients.

We present the following article in accordance with the REMARK reporting checklist (available at http://dx.doi. org/10.21037/tcr-20-1459).

\section{Methods}

\section{Patients and tissue samples}

Fifty Chinese patients with primarily advanced gastric adenocarcinoma, along with history of negative Helicobacter pylori infection and full data of clinical pathological observation, were carefully recruited in the present study (38). The patients underwent gastrectomy at the Department of Gastrointestinal Surgery, the First Affiliated Hospital of Anhui Medical University of China from April 2014 to December 2015. None of the cases received any chemotherapy or radiotherapy before surgery. All the patients received a conventional postoperative chemotherapy modality, i.e. postoperative intravenous infusion of oxaliplatin plus oral tegafur, three weeks per course, eight courses under adjuvant treatment, and 6 courses under palliative treatment. Dosages were supplied according to body weight and body surface area of the patients. Tumor tissue samples were obtained from the patient's surgical resection specimens as an experimental group. Ten adjacent non-cancerous gastric tissues from the incisions being more than $5 \mathrm{~cm}$ far away from the edge of tumor out of the patients with advanced gastric adenocarcinoma were collected. For each patient, the clinicopathological features, including age, gender, tumor location, tumor size distant metastasis, depth of invasion, lymph node metastasis, degree of differentiation and histological type were retrospectively collected. The depth of invasion, nodal metastasis, cancer embolus, differentiation degree, pathohistological type and TNM stage of the tumor were reclassified according to the eighth American Joint Committee on Cancer TNM classification by two independent gastroenterology pathologists. Survival follow-up survey was successfully obtained of all the patients until November 2017. Overall survival (OS) was defined as the time between the dates of surgery and death or the last visit. During the follow-up period, the death of the patient caused to tumor recurrence or metastasis, and not counted other diseases and accidental death. All procedures performed in studies involving human participants were in accordance with the ethical standards of the institutional research committee of Anhui Medical University of China (No. 20080253) and with the Helsinki Declaration (as revised in 2013). Written informed consent was obtained from the patient.

\section{Immunobistochemistry analysis}

Paraffin specimens of gastric cancer tissues were cut into 4- $\mu \mathrm{m}$ sections and baked in an incubator at $60{ }^{\circ} \mathrm{C}$ overnight. The specimens were deparaffinized in xylene and rehydrated through descending concentrations of ethanol. After washed twice in phosphate-buffered saline (PBS, $\mathrm{pH}$ 7.4) at room temperature (RT) for $5 \mathrm{~min}$, the endogenous peroxidase activity in the tissue sections was inhibited by incubation with $3 \% \mathrm{H}_{2} \mathrm{O}_{2}$ at RT for $10 \mathrm{~min}$. Antigen retrieval of the tissue sections was achieved by means of $0.01 \mathrm{M}$ citrate buffer (pH 6.0) at RT for $2 \mathrm{~min}$, followed by cooling for $2 \mathrm{~h}$. After washed in PBS and blocked with 5\% BSA in PBS at $\mathrm{RT}$ for $1 \mathrm{~h}$ to reduce nonspecific binding, the tissue sections were incubated with polyclonal rabbit-anti-human MR antibody (CD206, Abcam, Cambridge, USA) diluted 1:8,000 at $4{ }^{\circ} \mathrm{C}$ overnight. Antibody recognition was detected with peroxidase-conjugated goat anti-rabbit IgG secondary antibody (Zhongshan Goldenbridge Biotechnology Co., Ltd., Beijing, China) at RT for 30 minutes. After PBS washing, all the staining results were observed by DAB kit (DAB-0031, MXB Biotechnologies, Fujian, China). Finally, the sections were counterstained with hematoxylin.

\section{Lectin histochemistry}

Deparaffinized 4- $\mu \mathrm{m}$ thick sections of the primary gastric cancers were rehydrated through a series of graded ethanol solutions and incubated for $10 \mathrm{~min}$ at RT with $3 \% \mathrm{H}_{2} \mathrm{O}_{2}$. And washed in $0.01 \mathrm{M}$ PBS buffer ( $\mathrm{pH} 7.4)$ at $\mathrm{RT}$ three 
minutes for three times, the sections were incubated with biotinylated NPL (Vector, Burlingame, CA, USA) at PBS buffer-diluted concentration of 1:200 at RT for $30 \mathrm{~min}$. The sections were blocked with normal non-immune animal serum at RT for $15 \mathrm{~min}$. After carefully washed in PBS buffer, the sections were incubated with a streptavidinperoxidase complex (KIT-9710, MXB Biotechnologies, Fujian, China) at RT for 10 min. Finally, all the sections were visualized with DAB kit (DAB-0031, MXB Biotechnologies, Fujian, China), and counterstained with hematoxylin.

\section{Evaluation of immunochemistry (IHC) and lectin staining}

Positive staining of MR and NPL were observed in the cytoplasm and/or on the cell membrane of macrophages in tumor stromal tissues and appeared like brown granules. Histological observation and quantitative analysis of $\mathrm{NPL}^{+}$and $\mathrm{MR}^{+}$macrophages in the tumor stromal tissues were independently performed by two pathologists under Olympus CX31 microscope (Olympus, Center Valley, PA, USA). Five independent high-power fields (HPF, $\times 400$ ) in tumor tissues were selected for counting positive cells. The mean values of the positive cells were taken as the count values of $\mathrm{NPL}^{+}$macrophages and $\mathrm{MR}^{+}$macrophages, respectively. The receiver operating characteristics (ROC) curve analysis was used to calculate the cut-off values of $\mathrm{NPL}^{+}$and $\mathrm{MR}^{+}$macrophages in gastric cancer cases, which were divided into high-density group and low-density group. Based on the density of $\mathrm{NPL}^{+}$and $\mathrm{MR}^{+}$macrophages in tumor tissues, the patients were classified into four groups: ${ }^{\text {low }} \mathrm{NPL}^{+}$and ${ }^{\text {low }} \mathrm{MR}^{+}$group; ${ }^{\text {high }} \mathrm{NPL}^{+}$and ${ }^{\text {low }} \mathrm{MR}^{+}$ group; ${ }^{\text {low }} \mathrm{NPL}^{+}$and ${ }^{\text {high }} \mathrm{MR}^{+}$group; and ${ }^{\text {high }} \mathrm{NPL}^{+}$and ${ }^{\text {high }} \mathrm{MR}^{+}$ group (39). In the cancerous tissues, NPL was mainly located in the envelope or cytoplasm of gastric cancer cells. Staining intensity was scored as no staining $(-)$, weak $(+)$, moderate (++) and strong (+++).

\section{Statistical analysis}

Statistical analysis was performed using the SPSS 22.0 software. The immunohistochemical staining variables of MR and NPL between tumors and adjacent normal tissues were analyzed by $t$-test or chi-square $\left(\chi^{2}\right)$ test. Correlation analysis was performed with Spearman. Chi-square test or Fisher's exact test was used to analyze the correlation between immunohistochemical staining variables and clinicopathological parameters. Survival analysis was performed using the Kaplan-Meier analysis and log- rank test were used to assess statistical significance. Cox proportional hazards regression was employed for univariate and multivariate analysis of prognostic. A $\mathrm{p}$ value $\mathrm{P}<0.05$ represented a statistically significant difference.

\section{Results}

\section{Staining characteristics in gastric cancer}

As shown in Figure 1, the stromal $\mathrm{NPL}^{+}$cells mainly were the stromal macrophages adjacent to tumor tissues. NPL localized in the cytoplasm and membrane of the macrophages, which appeared coarse-grained brownyellow. In particular, dense and diffuse distribution of $\mathrm{NPL}^{+}$ macrophages were rich in the areas of inflammatory cell infiltration in gastric cancers. In cancer tissues, density distribution of $\mathrm{NPL}^{+}$macrophages were equal to inside and outside of the nest of tumors, but the distribution of NPL in normal gastric mucosa and in cancerous tissues varied. In normal gastric mucosa, NPL was mainly located in the cytoplasm of chief cells, parietal cells and neck cells, which were granular brownish yellow and densely stained (Figure 1A). In cancerous tissues expression of NPL mainly appeared in the cell membrane or cytoplasm of gastric cancer. NPL expression was observed in papillary adenocarcinoma (Figure 1C), tubular adenocarcinoma (Figure 1E), low differentiated adenocarcinomas (Figure 1G) and mucinous adenocarcinoma (Figure 1I). MR was mainly expressed in stromal macrophages in gastric cancer tissues. Although $\mathrm{MR}^{+}$macrophages were observed in normal gastric mucosal tissues (Figure $1 B$ ), more $\mathrm{MR}^{+}$macrophages appeared in gastric cancerous tissues. Counting number of $\mathrm{MR}^{+}$macrophages varied in papillary adenocarcinoma (Figure 1D), tubular adenocarcinoma (Figure 1F), low differentiated adenocarcinoma (Figure $1 H$ ) and mucinous adenocarcinoma (Figure 17). The distribution of $\mathrm{MR}^{+}$ macrophages in gastric cancer tissues was not equal. More $\mathrm{MR}^{+}$macrophages appeared in the periphery area of the tumor nests than inside of the nests of the tumors.

\section{Expression of $\mathrm{NPL}^{+}$and $\mathrm{MR}^{+}$macrophages in gastric cancer stromal tissues and their relationships with the clinicopathologic characteristics of the patients}

As shown in Table 1, the numbers of $\mathrm{NPL}^{+}$and $\mathrm{MR}^{+}$ macrophages in the stromal tissues of gastric cancer were significantly higher than those in adjacent noncancerous tissues ( $t$-test, $\mathrm{P}=0.006, \mathrm{P}<0.001)$, respectively. 

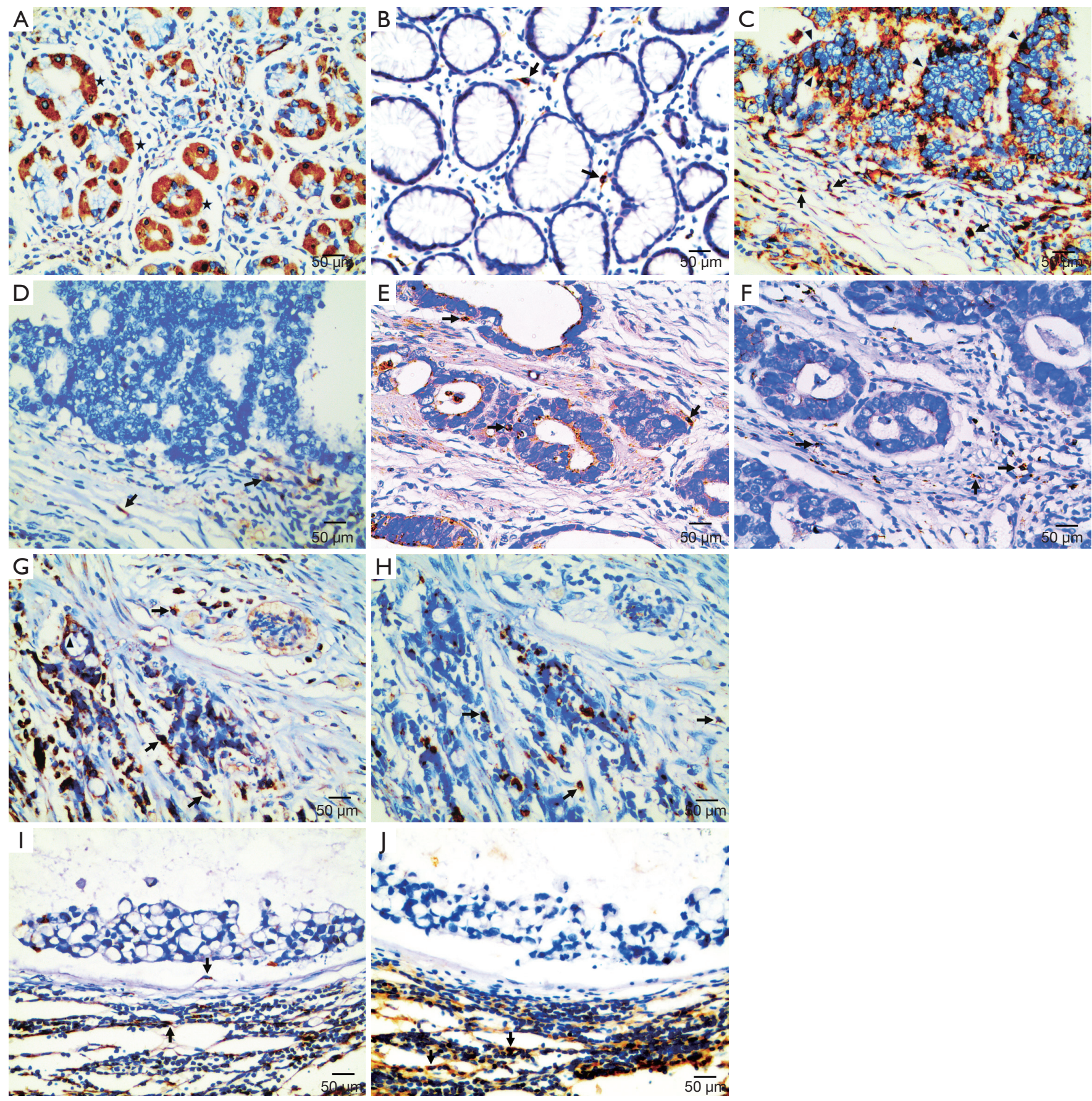

Figure 1 Expressions of Narcissus pseudonarcissus lectin (NPL) and mannose receptor (MR) in gastric non-cancerous and cancerous tissues. (A) (NPL) and (B) (MR): gastric non-cancerous tissues; (C) (NPL) and (D) (MR): papillary adenocarcinoma; (E) (NPL) and (F) (MR): tubular adenocarcinoma; (G) (NPL) and (H) (MR): poorly-differentiated adenocarcinoma and (I) (NPL) and (J) (MR): mucinous adenocarcinoma. On which, stars represented positive reactivity in gastric gland epithelial cells. Arrows indicated positive macrophages in tumor stromal tissue and triangles showed positive cancerous cells. Original magnification: $\times 400$. 
Table 1 Density difference of Narcissus pseudonarcissus lectin (NPL) ${ }^{+}$and mannose receptor $(\mathrm{MR})^{+}$macrophages in gastric cancer and adjacent nocancerous tissues (mean $\pm \mathrm{SD}$ )

\begin{tabular}{lcccc}
\hline Parameters & Group & Cases $(\mathrm{n})$ & Means $\pm \mathrm{SD}$ & $\mathrm{P}$ \\
\hline $\mathrm{NPL}{ }^{+}$macrophages & Cancer & 50 & $29.32 \pm 13.76$ & $0.006^{*}$ \\
& Controls & 10 & $20.14 \pm 7.41$ & \\
$\mathrm{MR}^{+}$macrophages & Cancer & 50 & $20.69 \pm 15.52$ & $<0.001^{*}$ \\
& Controls & 10 & $7.56 \pm 2.86$ \\
\hline
\end{tabular}

*, $\mathrm{P}<0.05 . \mathrm{SD}$, standard deviation.

Table 2 Expression of Narcissus pseudonarcissus lectin (NPL) in gastric cancerous and adjacent non-cancerous tissues

\begin{tabular}{|c|c|c|c|c|c|c|}
\hline Groups & Cases (n) & \multicolumn{5}{|c|}{ NPL } \\
\hline Cancer tissues & 50 & 10 & 21 & 13 & 6 & $0.003^{\star}$ \\
\hline Non-cancerous tissues & 10 & 0 & 1 & 9 & 0 & \\
\hline
\end{tabular}

*, $\mathrm{P}<0.05$.

The expression of NPL in the gastric cancer tissues was more predominant than that in the adjacent non-cancerous tissues (chi-square, $\mathrm{P}=0.003$, Table 2). Expression of both the molecules in the macrophages in the tumor tissues was negatively correlated $(\mathrm{r}=-0.363, \mathrm{P}=0.009)$. An association similarity between of $\mathrm{NPL}^{+}$and $\mathrm{MR}^{+}$macrophages was observed in the adjacent noncancerous tissues, but it appeared of no significance $(\mathrm{r}=-0.530, \mathrm{P}=0.115)$.

Effect of the expression of $\mathrm{NPL}^{+}$and $\mathrm{MR}^{+}$macrophages on the clinicopathological features of patients with gastric cancer were summarized in Table 3. The number of $\mathrm{MR}^{+}$ macrophages and expression of NPL in gastric cancerous cells were significantly correlated with TNM stage $(\mathrm{P}=0.009$ and $\mathrm{P}=0.020)$ and histopathological types of gastric cancer $(\mathrm{P}=0.040)$, respectively. No significant associations between IHC variables and other clinicopathological factors of the patients were observed $(\mathrm{P}>0.05)$.

\section{Relationship between NPL expression and MR ${ }^{+}$ macrophages number in tumor tissues and cumulative survival of the patients}

During the follow-up period, 23 patients died of tumor progression with an average survival time of 26.7 months (ranging from 23.0 to 30.4 months). The Kaplan-Meier survival model indicated that the OS of gastric cancer patients with high counting of $\mathrm{NLP}^{+}$macrophage was 30.35 months, which were significantly longer than in the patients with low counting of $\mathrm{NPL}^{+}$macrophages (21.9 months) ( $\mathrm{P}=0.037$, Figure 2). In addition, although the OS in the patients with negative NPL expression in tumor cells was 29.3 months, which was longer than that in the patients with positive NPL expression in tumor cells (24.2 months), but there was no statistical significance ( $\mathrm{P}=0.656$, Figure 3). The data of patients' cumulative survival period indicated that the expression of NPL in tumor cells would not significantly affect the prognosis of gastric cancer patients. The estimated survival time in the patients with low counting number of $\mathrm{MR}^{+}$macrophages (34.35 months) appeared longer than that in the patients with high counting number of $\mathrm{MR}^{+}$(22.04 months). A statistically significant difference was obtained $(\mathrm{P}=0.003$, Figure 4). Thus, our data indicated that $\mathrm{NPL}^{+}$macrophages and $\mathrm{MR}^{+}$macrophages in the tumor microenvironment would significantly affect the prognosis of patients with gastric cancer.

\section{Comparative analysis of NPL and MR provided more powerful prognostic value in gastric cancer patients}

As important tumor microenvironment components, mannose and MR were influenced the tumor development and progression. Thus, we hypothesized that combined analysis of NPL and MR would predict the prognosis of gastric cancer patients by evaluating both $\mathrm{NPL}^{+}$ macrophages and $\mathrm{MR}^{+}$macrophages in the tumor stroma. 
Table 3 Analysis between expression of Narcissus pseudonarcissus lectin (NPL) and mannose receptor (MR) in macrophages and cancerous tissues and clinicopathological characteristics in patients with gastric cancer $(\mathrm{n}=50)$

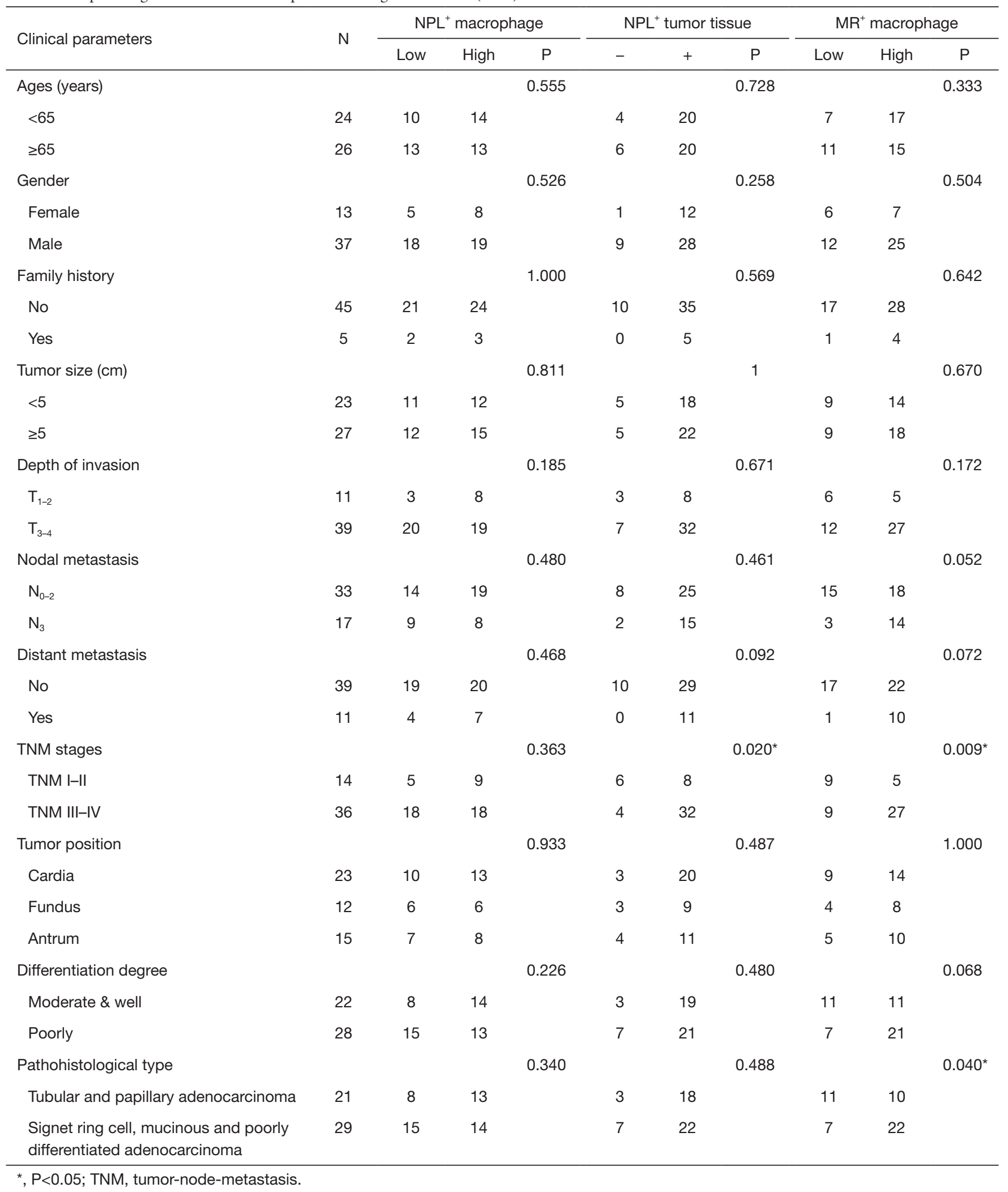




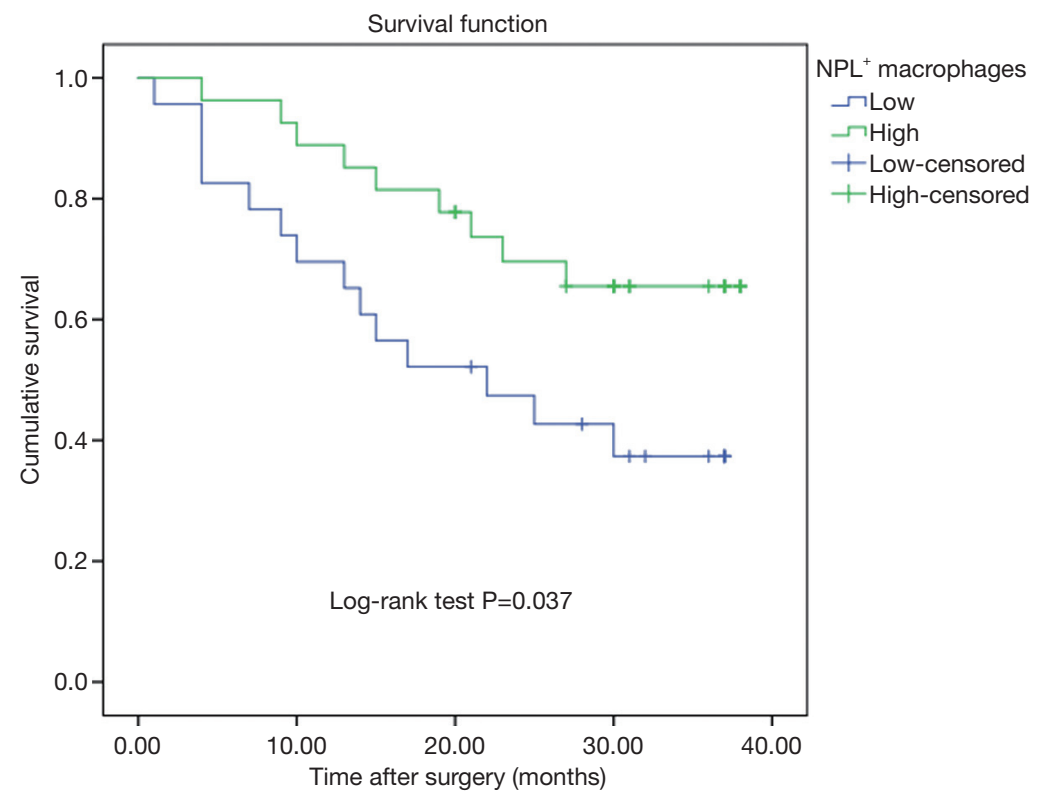

Figure 2 Kaplan-Meier survival curves of patients with gastric carcinoma in association with Narcissus pseudonarcissus lectin (NPL) ${ }^{+}$ macrophages in the tumor stromal tissues.

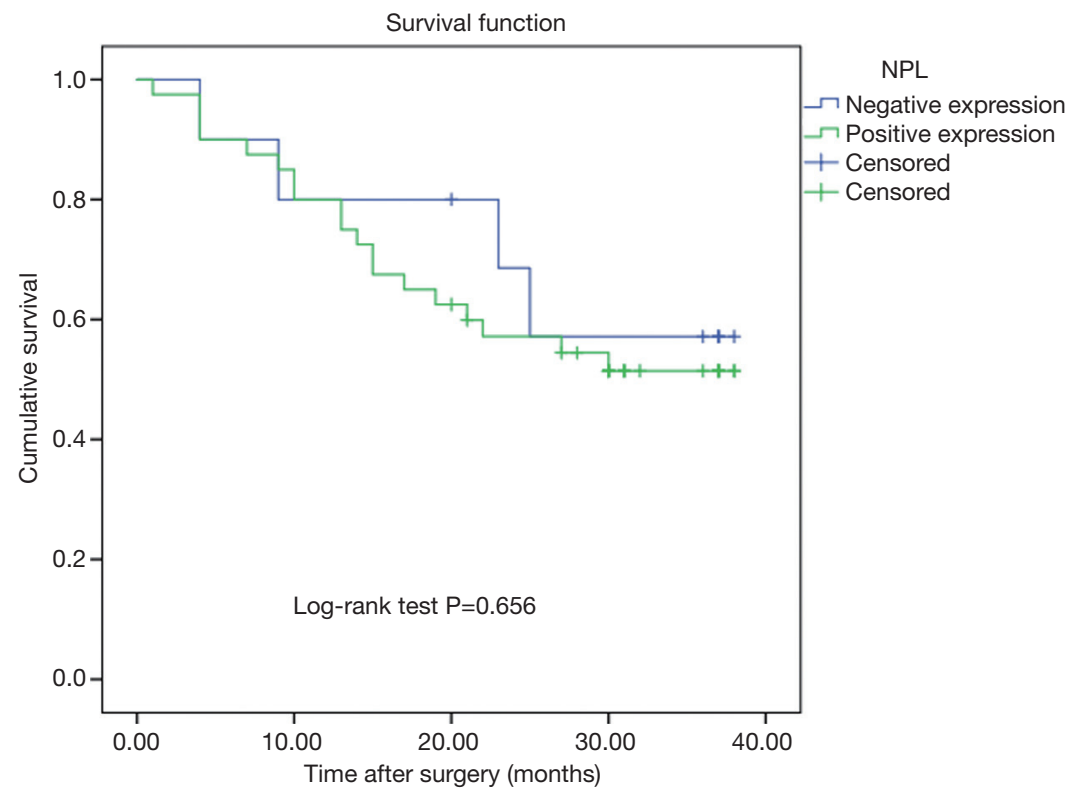

Figure 3 Kaplan-Meier survival curves of patients with gastric carcinoma in association with expression of Narcissus pseudonarcissus lectin (NPL) in tumor tissues.

Based on the distribution density of $\mathrm{NPL}^{+}$and $\mathrm{MR}^{+}$ macrophages in tumor tissues, the patients in this study were classified into four groups: (I) ${ }^{\text {high }} \mathrm{NPL}^{+}$and ${ }^{\text {low }} \mathrm{MR}^{+}$ group; (II) ${ }^{\text {low }} \mathrm{NPL}^{+}$and ${ }^{\text {low }} \mathrm{MR}^{+}$group; (III) ${ }^{\text {high }} \mathrm{NPL}^{+}$and
${ }^{\text {high }} \mathrm{MR}^{+}$group and (IV) ${ }^{\text {low }} \mathrm{NPL}^{+}$and ${ }^{\text {high }} \mathrm{MR}^{+}$group. The average OS in the four groups were $35.5,30.4,25.3$ and 19.4 months, respectively. The Kaplan-Meier survival curve showed a significant difference in OS among the four 


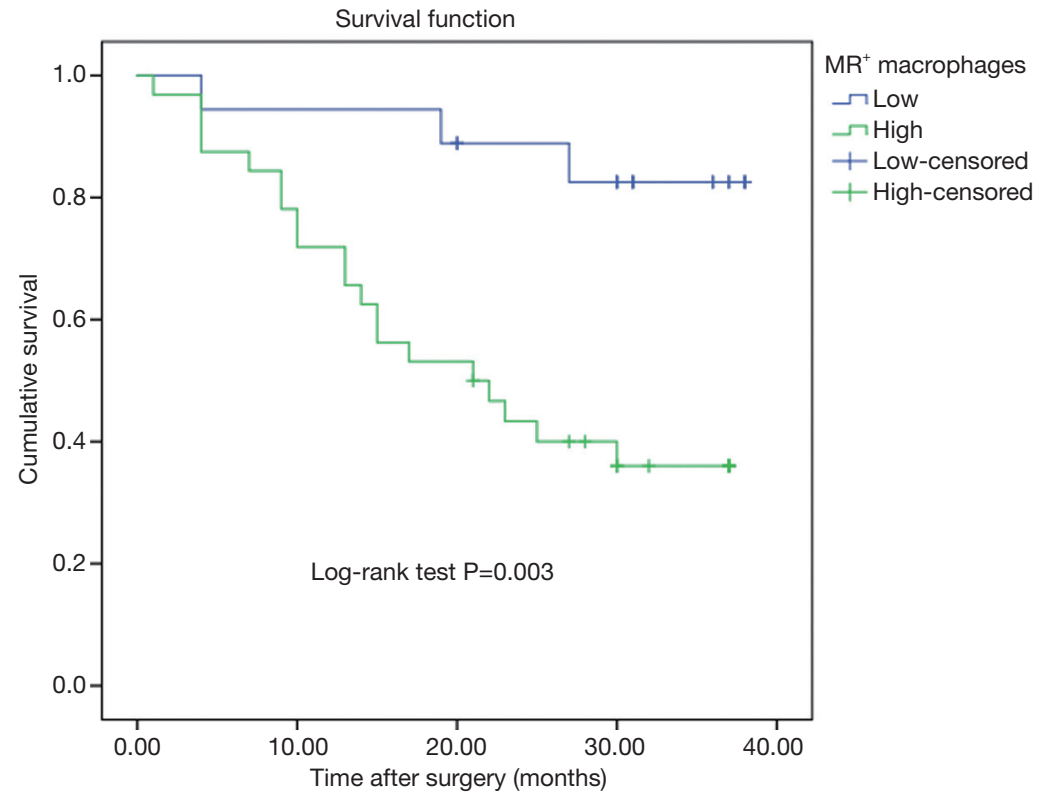

Figure 4 Kaplan-Meier survival curves of patients with gastric carcinoma in association with mannose receptor $(\mathrm{MR})^{+} \mathrm{macrophages}$ in tumor stromal tissues.

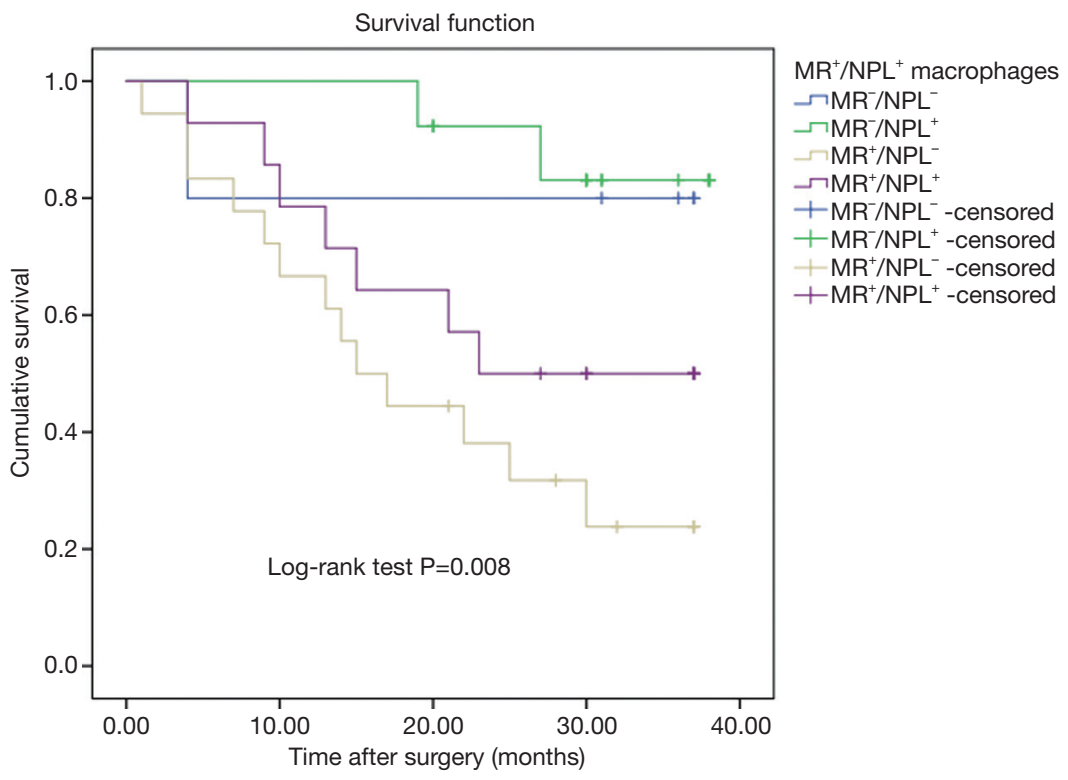

Figure 5 Kaplan-Meier curves for overall survival based on a comprehensive analysis of counting status of mannose receptor $(M R)^{+}$and Narcissus pseudonarcissus lectin (NPL) ${ }^{+}$macrophages in tumor stromal tissues of gastric cancer $(\mathrm{n}=50)$.

groups $(\mathrm{P}=0.008$, Figure 5$)$. The data suggested that the patients with appearance of more $\mathrm{MR}^{+}$macrophages and few $\mathrm{NPL}^{+}$macrophages in the stromal tissues of gastric cancer would hold shorter survival time. To a certain extent, it indicated that MR and mannose interaction affected the survival of patients with gastric cancer. Such a combined analysis of NPL and MR would be of more potential values for evaluating survival in gastric cancer patients than 
Table 4 Univariate and multivariate Cox regression analyses for overall survival of patients with gastric cancer $(\mathrm{n}=50)$

\begin{tabular}{|c|c|c|c|c|c|c|}
\hline Clinical parameters & \multicolumn{3}{|c|}{ Univariate analysis } & \multicolumn{3}{|c|}{ Multivariate analysis } \\
\hline Age (<60 vs. $\geq 60$ years) & 1.085 & $0.478-2.461$ & 0.845 & - & - & NA \\
\hline Gender (male vs. female) & 2.166 & $0.736-6.38$ & 0.161 & - & - & NA \\
\hline Family history (no vs. yes) & 0.672 & $0.157-2.859$ & 0.591 & - & - & NA \\
\hline Depth of invasion $\left(T_{1-2}\right.$ vs. $\left.T_{3-4}\right)$ & 1.606 & $0.989-2.608$ & 0.056 & - & - & NA \\
\hline Nodal metastasis $\left(\mathrm{N}_{0-2}\right.$ vs. $\left.\mathrm{N}_{3}\right)$ & 2.400 & $1.566-3.676$ & $<0.001^{*}$ & 1.887 & $1.220-2.918$ & $0.004^{*}$ \\
\hline Distant metastasis (no vs. yes) & 3.149 & $1.307-7.587$ & $0.011^{*}$ & - & - & NS \\
\hline TNM stages (I-II vs. III-IV) & 6.546 & $1.104-38.804$ & $0.039^{*}$ & - & - & NS \\
\hline Antrum vs. cardia & 1.599 & $0.486-5.257$ & 0.440 & & & NA \\
\hline Differentiation degree (moderate \& well vs. poorly) & 1.171 & $0.770-1.780$ & 0.460 & - & - & NA \\
\hline Pathohistological type & 1.238 & $0.535-2.861$ & 0.618 & - & - & NA \\
\hline $\mathrm{MR}^{+}$cell (high vs. low) & 5.272 & $1.560-17.820$ & $0.007^{*}$ & 3.853 & $1.119-13.271$ & $0.033^{*}$ \\
\hline $\mathrm{NPL}^{+}$cell (high vs. low) & 0.424 & $0.183-0.982$ & $0.045^{*}$ & - & - & NS \\
\hline $\mathrm{NPL}^{+}$tumor tissues $(-v s .+)$ & 1.274 & $0.433-3.747$ & 0.660 & - & - & NA \\
\hline
\end{tabular}

*, P<0.05. OS, overall survival; TNM, tumor-node-metastasis; HR, hazard ratio; Cl, confidential interval; NA, not applicable; NS, not significant; NPL, Narcissus pseudonarcissus lectin; MR, mannose receptor.

individual factor analysis.

\section{Analysis of COX regression model for prognosis related factors of gastric cancer}

The clinical and pathological biological parameters that would be related to the prognosis of gastric cancer patients and the expression of NPL and MR in gastric cancer tissues were analyzed by Cox regression. Univariate analysis of prognostic factors indicated that tumor size $(\mathrm{P}=0.048)$, lymph node metastasis $(\mathrm{P}<0.001)$, distant metastasis $(\mathrm{P}=0.011)$, TNM stage $(\mathrm{P}=0.039)$, and counting numbers of $\mathrm{MR}^{+}$macrophages $(\mathrm{P}=0.007)$ and $\mathrm{NPL}^{+}$macrophages $(\mathrm{P}=0.045)$ in tumor tissues revealed significant impacts on prognosis of the patients. Multivariate survival analysis further demonstrated that lymph node metastasis [hazard ratio $(\mathrm{HR})=1.887,95 \%$ confidence interval $(\mathrm{CI}): 1.220$ 2.918, $\mathrm{P}=0.004]$ and $\mathrm{MR}^{+}$macrophages number in tumor tissues $(\mathrm{HR}=3.853$, 95\% CI: $1.119-13.271, \mathrm{P}=0.033)$ were independent predictors of poor prognosis for OS in the patients (Table 4).

\section{Discussion}

This study demonstrated the hypothesis that MR and its ligand-mannose were highly expressed either in the macrophages of tumor stromal tissues or carcinoma cells of gastric cancer. We found that the counting numbers of $\mathrm{MR}^{+}$ macrophages and $\mathrm{NPL}^{+}$macrophages in the tumor stromal tissues were negatively correlated $(\mathrm{r}=-0.363, \mathrm{P}=0.009)$. Our observation revealed that regardless of the fact that NPL expression in tumor tissue cells was not associated with $\mathrm{OS}$ in gastric cancer patients $(\mathrm{P}=0.656)$, the counting numbers of $\mathrm{MR}^{+}$macrophages and $\mathrm{NPL}^{+}$macrophages in the tumor stromal tissues were significantly correlated with OS $(\mathrm{P}=0.003 ; \mathrm{P}=0.037)$, respectively. Cox regression analysis confirmed that $\mathrm{MR}$ was an independent prognostic factor $(\mathrm{P}=0.033)$. To the best of our knowledge, it was the first time to investigate the interaction between MR and its ligand-mannose in gastric cancer tissues and to evaluate 
their prognostic value for gastric cancer patients. Interaction of both the molecules would affect the prognosis of gastric cancer patients.

The tumor microenvironment consists of many types of cells and cytokines. Cross-talks between tumor cells and the ambient microenvironment affected tumor progression and metastasis. In particular, MR and mannose can be overexpressed in various tumor tissues, for example, colon cancer (14) and esophageal cancer (40). In this study, we used an anti-human MR antibody (CD206) as a MR marker and NPL as a mannose marker. We found that MR and mannose were highly expressed in tissues of gastric cancer patients. MR was localized in macrophages. NPL was observed in macrophages and tumor cells. Both the molecules were related to the clinicopathological and biological characteristics of the gastric cancer patients, of which the counting number of $\mathrm{MR}^{+}$macrophages and expression of NPL in gastric cancerous cells were significantly correlated with TNM stage $(\mathrm{P}=0.009$ and $\mathrm{P}=0.020$ ), respectively. A previous investigation demonstrated that under hypoxic conditions, MR was highly expressed on the inner surface of tumor blood vessels, and targeted silencing MR could inhibit tumor growth (18). Similarly, an additional study revealed that the serum metabolite mannose was abnormally elevated in breast cancer patients, especially in advanced stage of the patients (27). Increased mannose expression, via promoting tumor cell interaction with MR, was involved in tumor growth, adhesion, and metastasis $(41,42)$. Therefore, $M R$ and mannose might promote the growth, proliferation and invasion of gastric cancer. In this study we demonstrated that $\mathrm{MR}^{+}$macrophages conferred a poor prognosis for patients with gastric cancer and appeared as one of the independent prognostic factors, in consistence with the previous reports $(22,37)$. In contrast to $\mathrm{MR}^{+}$macrophage infiltration, the patient with few $\mathrm{NPL}^{+}$macrophages in tumor stromal tissues had a shorter survival time. Although previous studies indicated mannose might be used as a prognostic biomarker for cancer patients, only few reports highlighted the clinical significance of mannose on tumors. It was pointed out that serum D-mannose levels were significantly associated with recurrence and OS in patients with esophageal cancer (43). Patients at the advanced stages (stage III and IVa) had higher levels of serum D-mannose than those at the early stage. High level of serum D-mannose was observed in patients with a higher survival rate than those with low survival rates (43). This metabolic change might be due to abnormally anabolic requirements of cancer cells and incomplete abnormal glycosylation processes (42).

Previous investigations highlighted the prognostic value of individual MR or mannose in cancer but did not provide a comparative analysis of MR and mannose $(22,43)$. As a result of abundant distribution of MR and mannose in tumor tissues, a combined analysis for MR and mannose seemed to be of potential values in objectively evaluating consequences of patients with tumors. Although ${ }^{\text {low }} \mathrm{NPL}^{+} /$ ${ }^{\text {low }} \mathrm{MR}^{+}$and ${ }^{\text {high }} \mathrm{NPL}^{+} /{ }^{\text {high }} \mathrm{MR}^{+}$counting revealed the intermediate OS effect, potentially attributing to functional counterbalance regulated by NPL and $\mathrm{MR},{ }^{\text {low }} \mathrm{NPL}^{+} /$ ${ }^{\text {high }} \mathrm{MR}^{+}$macrophage counting were significantly associated with a poor prognosis $(\mathrm{P}=0.008)$, indicating that survival time of patients with more $\mathrm{MR}^{+}$macrophages and fewer $\mathrm{NPL}^{+}$macrophages in gastric cancer stromal tissues were quite shorter survival. Therefore, ${ }^{\text {high }} \mathrm{NPL}^{+} /{ }^{\text {low }} \mathrm{MR}^{+}$counting would serve as a favorable prognostic factor for evaluation of OS. To some extent, it suggested that the interaction of MR and mannose would affect the survival of patients with gastric cancer. Poor prognosis in the patients with ${ }^{\text {low }} \mathrm{NPL}^{+} /$ ${ }^{\text {high }} \mathrm{MR}^{+}$macrophage counting might attribute to an immune profile of M2 macrophage polarization. It was reported that more M2 macrophages infiltrated in cancer tissues and was often used as an independent risk factor for prognosis in patients with gastric cancer $(14,37)$. A previous study demonstrated that MR, via binding its konjac mannose ligand, promoted the polarization of macrophages to M2 macrophages. Konjac mannose ligand induced the secretion of IL-10 as well as decreased the expression of IL-6 and TNF- $\alpha$ by macrophages, functioning in anti-inflammatory and promoted tumor progression (44). Mannose, a class of polysaccharide-derived immunomodulators, interacted with MR to stimulate macrophage activity in the body and triggered an intracellular signaling cascade that mediated anti-inflammatory and pro-inflammatory responses $(45,46)$. In such a extracellular environment, the strong binding between the mannose and the carbohydrate-recognition domain (CRD) in the MR molecule caused oligomerization and cross-linking of the receptor protein, and activated the macrophage to enhance its immune function through a series of signal transduction processes (47). Li et al. reported that MR was crucial for the immune response to Ganoderma atrum polysaccharides (PSG-1), because of the elevation of MR in association with increases of phagocytosis and concentrations of IL- $1 \beta$ and TNF- $\alpha$ in normal macrophages (48). These results indicated that MR binding to ligand was one of the important mechanisms mediating the immune regulation of tumors in vivo, which affected the prognosis of patients with 
gastric cancer.

More interestingly, we found that the counting numbers of $\mathrm{MR}^{+}$macrophages and $\mathrm{NPL}^{+}$macrophages in the tumor stromal tissues were negatively correlated, which might potentially reflect a mutual antagonism between MR and mannose. A previous study indicated that MR could remove polysaccharide molecules from cancerous tissues as a scavenger receptor (6). Moreover, mannose, as the natural ligand of MR, binds to the C-type lectinlike domains of MR and mannose dose-dependently increased levels of macrophage MR (46). Therefore, we supposed that the counting of $\mathrm{MR}^{+}$macrophages would drastically decrease within the tumor tissues, because a large amount of intratumor MR was cleaned by a mechanism of phagocytosis. Also, in this study, we observed that distribution of both the $\mathrm{MR}^{+}$macrophages and $\mathrm{NPL}^{+}$ macrophages in gastric cancer tissues and the adjacent noncancerous tissues were uneven. $\mathrm{MR}^{+}$macrophages mainly located in the area near the cancer nests, similarly to the previous investigation (49). Both in the intratumor and the adjacent non-cancerous areas, $\mathrm{NPL}^{+}$macrophages were much more abundant than $\mathrm{MR}^{+}$macrophages. Although it was reported that NPL was localized in stromal macrophages and lymphocytes (50), it was not difficult to distinguish the cells because of different morphologies of lymphocytes and macrophages. This study revealed that NPL expression was not only involved in gastric cancerous stromal macrophages, but also reflected functional activity of epithelial cells of the gastric mucosa and enrichment in gastric cancer cells. NPL expression in lymphocytes in gastric stromal tissue appeared negative. Although there was a previous investigation visualizing that $M R$ staining was strong in the nucleus and cytoplasm of gastric cancer cells (15), more additional investigations were lack of evidences showing MR positive staining in gastric cancer cells, indicating that such a MR positive response in gastric cancer cells would attribute to a potentially artificial staining or unspecific contamination. We supposed that high expression of MR in gastric cancer tissues would at least partially reflect infiltration of a certain number of M2 macrophages and showed a correlation with poor survival of the patients.

There were several potential shortages of this version of the study calling for further evaluation, for example, (I) the panel of patients selected was relatively limited. Increasing numbers of clinical specimen panels would be able to more objectively evaluate relationship of MR and NPL in gastric cancer tissues and (II) the methodology used was relatively simple. Based on our previous data in which a significant serological expression of mannose in gastric cancer patients was found (38), we identified the histological localization of mannose in the identical patients with gastric cancer, as described by the previous investigation (21). Potential target proteins rich in NPL in the gastric cancer tissues would be worthy to explore further.

\section{Conclusions}

In conclusion, to the best of our knowledge, this was the first study to carry out such a concurrent analysis on the expression and distribution of NPL and MR in gastric cancer tissues. We found that there was a significantly negative correlation between the expression of NPL and MR in gastric cancer stromal tissues. Mannose might affect the progression of gastric cancer by regulating MR expression. The patients with ${ }^{\text {low }} \mathrm{NPL}^{+} /{ }^{\text {high }} \mathrm{MR}^{+}$expression in gastric cancerous stromal tissues held a significantly shortest survival time, suggesting that MR interacted with its ligand-mannose in gastric cancer tissues, both affecting the progression and prognosis of patients with gastric cancer. MR and NPL would become new biomarkers for survival assessment for patients with gastric cancer. Obviously, further studies to investigate the molecular mechanisms of MR and NPL in the progression and metastasis of gastric cancer are needed.

\section{Acknowledgments}

We thank all of the subjects enrolled in this study.

Funding: This study was supported by the Scientific Research Foundation of the Institute for Translational Medicine of Anhui Province (2017zhyx37).

\section{Footnote}

Reporting Checklist: The authors have completed the REMARK reporting checklist. Available at http://dx.doi. org/10.21037/tcr-20-1459

Data Sharing Statement: Available at http://dx.doi. org/10.21037/tcr-20-1459

Peer Review File: Available at http://dx.doi.org/10.21037/tcr20-1459

Conflicts of Interest: All authors have completed the ICMJE 
uniform disclosure form (available at http://dx.doi. org/10.21037/tcr-20-1459). The authors have no conflicts of interest to declare.

Ethical Statement: The authors are accountable for all aspects of the work in ensuring that questions related to the accuracy or integrity of any part of the work are appropriately investigated and resolved. This study was approved by the Ethics Committee of the Anhui Medical University of China (No. 20080253) and conducted in accordance with the Declaration of Helsinki (as revised in 2013). The signed informed consents of all the participants were obtained.

Open Access Statement: This is an Open Access article distributed in accordance with the Creative Commons Attribution-NonCommercial-NoDerivs 4.0 International License (CC BY-NC-ND 4.0), which permits the noncommercial replication and distribution of the article with the strict proviso that no changes or edits are made and the original work is properly cited (including links to both the formal publication through the relevant DOI and the license). See: https://creativecommons.org/licenses/by-nc-nd/4.0/.

\section{References}

1. Ferlay J, Soerjomataram I, Dikshit R, et al. Cancer incidence and mortality worldwide: sources, methods and major patterns in GLOBOCAN 2012. Int J Cancer 2015;136:E359-86.

2. Chen $W$, Zheng R, Baade PD, et al. Cancer statistics in China, 2015. CA Cancer J Clin 2016;66:115-32.

3. Sawaki K, Kanda M, Kodera Y. Review of recent efforts to discover biomarkers for early detection, monitoring, prognosis, and prediction of treatment responses of patients with gastric cancer. Expert Rev Gastroenterol Hepatol 2018;12:657-70.

4. Sawada T, Yashiro M, Sentani K, et al. New molecular staging with G-factor supplements TNM classification in gastric cancer: a multicenter collaborative research by the Japan Society for Gastroenterological Carcinogenesis G-Project committee. Gastric Cancer 2015;18:119-28.

5. Azad AK, Rajaram MV, Schlesinger LS. Exploitation of the Macrophage Mannose Receptor (CD206) in Infectious Disease Diagnostics and Therapeutics. J Cytol Mol Biol 2014;1:1000003.

6. Taylor PR, Gordon S, Martinez-Pomares L. The mannose receptor: linking homeostasis and immunity through sugar recognition. Trends Immunol 2005;26:104-10.

7. He LZ, Weidlick J, Sisson C, et al. Toll-like receptor agonists shape the immune responses to a mannose receptor-targeted cancer vaccine. Cell Mol Immunol 2015;12:719-28.

8. Ramakrishna V, Treml JF, Vitale L, et al. Mannose receptor targeting of tumor antigen pmel17 to human dendritic cells directs anti-melanoma $T$ cell responses via multiple HLA molecules. J Immunol 2004;172:2845-52.

9. Faddaoui A, Bachvarova $M$, Plante $M$, et al. The mannose receptor LY75 (DEC205/CD205) modulates cellular phenotype and metastatic potential of ovarian cancer cells. Oncotarget 2016;7:14125-42.

10. Pouniotis DS, Plebanski M, Apostolopoulos V, et al. Alveolar macrophage function is altered in patients with lung cancer. Clin Exp Immunol 2006;143:363-72.

11. Andersen MN, Andersen NF, Rodgaard-Hansen S, et al. The novel biomarker of alternative macrophage activation, soluble mannose receptor (sMR/sCD206): Implications in multiple myeloma. Leuk Res 2015;39:971-5.

12. Fang J, Tao T, Zhang Y, et al. A barcode mode based on glycosylation sites of membrane type mannose receptor as a new potential diagnostic marker for breast cancer. Talanta 2019;191:21-6.

13. Zarif JC, Baena-Del Valle JA, Hicks JL, et al. Mannose Receptor-positive Macrophage Infiltration Correlates with Prostate Cancer Onset and Metastatic Castration-resistant Disease. Eur Urol Oncol 2019;2:429-36.

14. Ding D, Yao Y, Yang C, et al. Identification of mannose receptor and CD163 as novel biomarkers for colorectal cancer. Cancer Biomark 2018;21:689-700.

15. Liu DR, Guan QL, Gao MT, et al. Mannose receptor as a potential biomarker for gastric cancer: a pilot study. Int J Biol Markers 2017;32:e278-83.

16. Zhang $H$, Wang $X$, Shen $Z$, et al. Infiltration of diametrically polarized macrophages predicts overall survival of patients with gastric cancer after surgical resection. Gastric Cancer 2015;18:740-50.

17. Matsui M, Shimizu Y, Kodera Y, et al. Targeted delivery of oligomannose-coated liposome to the omental micrometastasis by peritoneal macrophages from patients with gastric cancer. Cancer Sci 2010;101:1670-7.

18. Movahedi K, Schoonooghe S, Laoui D, et al. Nanobodybased targeting of the macrophage mannose receptor for effective in vivo imaging of tumor-associated macrophages. Cancer Res 2012;72:4165-77.

19. Scodeller P, Simon-Gracia L, Kopanchuk S, et al. Precision Targeting of Tumor Macrophages with a CD206 
Binding Peptide. Sci Rep 2017;7:14655.

20. Allavena P, Chieppa M, Bianchi G, et al. Engagement of the mannose receptor by tumoral mucins activates an immune suppressive phenotype in human tumor-associated macrophages. Clin Dev Immunol 2010;2010:547179.

21. Yin S, Huang J, Li Z, et al. The Prognostic and Clinicopathological Significance of Tumor-Associated Macrophages in Patients with Gastric Cancer: A MetaAnalysis. PLoS One 2017;12:e0170042.

22. Räihä MR, Puolakkainen PA. Tumor-associated macrophages (TAMs) as biomarkers for gastric cancer: A review. Chronic Dis Transl Med 2018;4:156-63.

23. Tang XL, Yuan CH, Ding Q, et al. Selection and identification of specific glycoproteins and glycan biomarkers of macrophages involved in Mycobacterium tuberculosis infection. Tuberculosis (Edinb) 2017;104:95-106.

24. Barkhordari A, Stoddart RW, McClure SF, et al. Lectin histochemistry of normal human lung. J Mol Histol 2004;35:147-56.

25. Alton G, Hasilik M, Niehues R, et al. Direct utilization of mannose for mammalian glycoprotein biosynthesis. Glycobiology 1998;8:285-95.

26. Sanchez-Espiridion B, Liang D, Ajani JA, et al. Identification of Serum Markers of Esophageal Adenocarcinoma by Global and Targeted Metabolic Profiling. Clin Gastroenterol Hepatol 2015;13:17301737.e9.

27. Jobard E, Pontoizeau C, Blaise BJ, et al. A serum nuclear magnetic resonance-based metabolomic signature of advanced metastatic human breast cancer. Cancer Lett 2014;343:33-41.

28. van Damme EJM, Allen AK, Peumans WJ, editors. Related mannose-specific lectins from different species of the family Amaryllidaceae. Physiol Plant 1988;73:52-7.

29. Sauerborn MK, Wright LM, Reynolds CD, et al. Insights into carbohydrate recognition by Narcissus pseudonarcissus lectin: the crystal structure at $2 \mathrm{~A}$ resolution in complex with alpha1-3 mannobiose. J Mol Biol 1999;290:185-99.

30. Li C, He Q, Ma J, et al. Glycan profiling on the cell membrane of normal mucosal epithelial cells and gastric cancer cells detected with lectin array. Journal of China Medical University 2009;38:807-13.

31. Jörns J, Mangold U, Neumann U, et al. Lectin histochemistry of the lymphoid organs of the chicken. Anat Embryol (Berl) 2003;207:85-94.

32. Barkhordari A, Stoddart R, McClure SF, et al. Lectin histochemistry of cholesterol cleft granulomas in nonspecific interstitial pneumonia (NSIP). Medical Journal of The Islamic Republic of Iran (MJIRI) 2005;19:57-63.

33. Yang L, Zhang Y. Tumor-associated macrophages: from basic research to clinical application. J Hematol Oncol 2017;10:58.

34. Schlesinger LS, Hull SR, Kaufman TM. Binding of the terminal mannosyl units of lipoarabinomannan from a virulent strain of Mycobacterium tuberculosis to human macrophages. J Immunol 1994;152:4070-9.

35. Shibata Y, Metzger WJ, Myrvik QN. Chitin particleinduced cell-mediated immunity is inhibited by soluble mannan: mannose receptor-mediated phagocytosis initiates IL-12 production. J Immunol 1997;159:2462-7.

36. Li T, Mo C, Qin X, et al. Glycoprofiling of Early Gastric Cancer Using Lectin Microarray Technology. Clin Lab 2018;64:153-61.

37. Ding D, Song Y, Yao Y, et al. Preoperative serum macrophage activated biomarkers soluble mannose receptor (sMR) and soluble haemoglobin scavenger receptor (sCD163), as novel markers for the diagnosis and prognosis of gastric cancer. Oncol Lett 2017;14:2982-90.

38. Gao Y, Li SG, Liu Q, et al. Establishment of a 1, 4, 7, 10-tetraazacyclododecane-1,4,7,10-tetraacetic acid monoN-hydroxysuccinimide ester (DOTA-NHS-ester) based lectin microarray for efficiently detecting serum glycans in gastric cancers. Anal Biochem 2020;597:113686.

39. Dong P, Ma L, Liu L, et al. CD86(+)/CD206(+), Diametrically Polarized Tumor-Associated Macrophages, Predict Hepatocellular Carcinoma Patient Prognosis. Int J Mol Sci 2016;17:320.

40. Mechref Y, Hussein A, Bekesova S, et al. Quantitative serum glycomics of esophageal adenocarcinoma and other esophageal disease onsets. J Proteome Res 2009;8:2656-66.

41. Mendoza L, Olaso E, Anasagasti MJ, et al. Mannose receptor-mediated endothelial cell activation contributes to B16 melanoma cell adhesion and metastasis in liver. J Cell Physiol 1998;174:322-30.

42. de Leoz ML, Young LJ, An HJ, et al. High-mannose glycans are elevated during breast cancer progression. Mol Cell Proteomics 2011;10:M110.002717.

43. Gu J, Liang D, Pierzynski JA, et al. D-mannose: a novel prognostic biomarker for patients with esophageal adenocarcinoma. Carcinogenesis 2017;38:162-7.

44. Gan J, Dou Y, Li Y, et al. Producing anti-inflammatory macrophages by nanoparticle-triggered clustering of mannose receptors. Biomaterials 2018;178:95-108.

45. Muller CD, Schuber F. Neo-mannosylated liposomes: 
synthesis and interaction with mouse Kupffer cells and resident peritoneal macrophages. Biochim Biophys Acta 1989;986:97-105.

46. Xu XL, Zhang $\mathrm{P}$, Shen YH, et al. Mannose prevents acute lung injury through mannose receptor pathway and contributes to regulate PPAR $\gamma$ and TGF- $\beta 1$ level. Int J Clin Exp Pathol 2015;8:6214-24.

47. Opanasopit P, Higuchi Y, Kawakami S, et al. Involvement of serum mannan binding proteins and mannose receptors in uptake of mannosylated liposomes by macrophages. Biochimica et biophysica acta 2001;1511:134-45.

Cite this article as: Liu SS, Gao Y, Yin SP, Ye L, Song ZJ, Liu Q, Li SG, Du WD. Expression of Narcissus pseudonarcissus lectin and mannose receptor positive macrophages predict progression and prognosis of patients with gastric cancer. Transl Cancer Res 2020;9(10):5979-5993. doi: 10.21037/tcr-20-1459
48. Li WJ, Tang XF, Shuai XX, et al. Mannose Receptor Mediates the Immune Response to Ganoderma atrum Polysaccharides in Macrophages. J Agric Food Chem 2017;65:348-57.

49. Ren CX, Leng RX, Fan YG, et al. Intratumoral and peritumoral expression of CD68 and CD206 in hepatocellular carcinoma and their prognostic value. Oncol Rep 2017;38:886-98.

50. Paessens LC, Garcia-Vallejo JJ, Fernandes RJ, et al. The glycosylation of thymic microenvironments. A microscopic study using plant lectins. Immunol Lett 2007;110:65-73. 